\title{
GPTEM: Grupo de Pesquisa sobre Tecnologias na Educação Matemática
}

\author{
Marco Aurélio Kalinke ${ }^{1}$ \\ Departamento de Matemática - Universidade Tecnológica Federal do Paraná (UTFPR). \\ Programa de Pós-Graduação em Educação em Ciências e em Matemática - \\ Universidade Federal do Paraná (PPGECM/UFPR) \\ Curitiba - PR - Brasil \\ kalinkedutfpr.edu.br, http://gptem5.wix.com/gptem
}

\section{Objetivos do Grupo}

O objetivo geral do grupo é estudar o uso de novas tecnologias em Educação Matemática, atuando na sua compreensão, domínio e desenvolvimento de novos recursos tecnológicos. A proposta é pesquisar a utilização das TIC em práticas relacionadas ao ensinar e aprender Matemática, particularmente àquelas relacionadas ao uso de vídeos, Objetos de Aprendizagem, Lousas Digitais, tablets, tecnologias vestíveis e smartphones, e suas relações com Materiais Didáticos de Matemática, atuando na compreensão, domínio e desenvolvimento de novos Objetos de Aprendizagem e novas propostas de atividades interativas para o ensino da Matemática.

\section{Universidades e Instituições de Pesquisa participantes}

O grupo está relacionado ao Programa de Pós-Graduação em Educação em Ciências e em Matemática (PPGECM) da UFPR, ao Departamento Acadêmico de Matemática (DAMAT) da UTFPR e à Coordenação de Tecnologia na Educação - Câmpus Curitiba da UTFPR (COTED).

\section{Pesquisadores/Desenvolvedores envolvidos}

Alcione Cappelin; Bruna Derossi; Carolina Soares Bueno; Cinthia Domit Zaniolo Renaux; Cristiane Straioto Diniz; Eloisa Rosotti Navarro; Fabiane Heisler; Ivanete Zuchi Siple; Laíza Erler Janegitz; Luciane Ferreira Mocrosky; Luciane Mulazani dos Santos; Marcia Beatriz Amplatz; Marco Aurélio Kalinke; Mariana da Silva Nogueira Ribeiro; Renata Balbino; Tania Preto.

\section{Principais projetos (concluídos/em andamento)}

O Uso da Lousa Digital na Rede Estadual de Ensino do Paraná; A Utilização de Recortes de Filmes como Objeto de Aprendizagem no Conteúdo de Função do $1^{\circ}$ e $2^{\circ}$ Graus; Caracterização e Aplicação dos Objetos Virtuais de Aprendizagem Propostos pelo Programa Nacional do Livro Didático (PNLD) para a Disciplina de Matemática; Aprendizagem Colaborativa: Um estudo com a Ferramenta Wiki com os alunos do $9^{\circ}$ ano do ensino fundamental; Utilização de Tecnologias de Informação e Comunicação na alfabetização matemática; As novas tecnologias na formação do professor de matemática e suas práticas pedagógicas; Ensino e aprendizagem de conteúdos de matemática em um ambiente dinâmico e interativo; $\mathrm{O}$ uso da lousa digital interativa no ambiente escolar como objeto de aprendizagem. 